\title{
Accounting for counting: A unified semantics for measure terms and classifiers*
}

\author{
Gregory Scontras \\ Harvard University
}

\begin{abstract}
This paper develops and extends the semantic account of morphological number marking in the presence of numerals from Scontras 2013. The account handles variation in patterns of number marking along two dimensions: crosslinguistically, between languages that either necessitate or prohibit singular morphology in the presence of numerals greater than 'one'; and within one and the same language: English. The proposed semantics accounts for both sorts of variation by assuming flexibility in the selection of the measure relevant to the one-ness presupposition of the morphological singular form. The system also provides an explanation for the Slobin-Greenberg-Sanches Generalization, which states that no classifier language has obligatory number marking: by aligning the semantics of counting in both number marking and classifier languages, and by assuming that nouns in classifier languages denote kinds, the semantic contribution of number marking is necessarily redundant in classifier languages. A system of obligatory number marking only surfaces in languages where it delivers otherwise unrecoverable information about the number of intended referents.
\end{abstract}

Keywords: numerals, number marking, amount terms, classifiers

\section{Introduction}

Numerals like one, two, or three reference numbers (1,2, and 3, respectively), and when embedded in larger linguistic contexts they serve to specify an amount or number of objects. In other words, numerals count, and as they do so they nontrivially affect not only the resulting meaning but also the form of the words with which they appear. One book contrasts with two books, firstly on how many objects are implicated and secondly on the numeral and number morphology expressed. In the case of one book, we imagine a single book and find a noun in the singular form; with two books we imagine more than one book and the noun appears morphologically plural. Already we see that numerals play a central role in determining both

* This paper would not have been possible without the generous help of many people. Foremost among them is Gennaro Chierchia, who provided guidance and support at every step. Uli Sauerland graciously shared his time to discuss the ideas herewith presented. Beste Kamali and Süleyman Ulutaş assisted with the Turkish facts. Finally, I thank the audience and organizers of SALT 23.

(C)2013 Scontras 
the meaning and the morphology of the nouns with which they occur. This paper investigates the means by which we count with numerals, and the effect numerals have on the determination of morphological number. Doing so necessitates not only a semantics for numerals, but also an account of morphological number such that it is sensitive to the numerals present.

Our starting point is the semantics of morphological number proposed in Scontras 2013, itself a development of the presuppositional account of morphological number from Sauerland 2003. This system attributes a one-ness presupposition to the morphological singular form whereby the nouns that express it must number (or measure) 1 in some salient sense. Variation in the selection of the measure relevant to this one-ness presupposition accounts for diverging patterns of number marking in the presence of numerals, both within and across languages. As we explicate this system of number marking, we commit ourselves to a semantics for numerals and for measurement more broadly. Both the semantics of morphological number and the semantics of numerals inform the second aim of our study: counting and the absence of number marking in classifier languages.

The resulting proposal attributes measurement and therefore counting not to numerals proper, but to a functional projection $\mathrm{M}$ (easure)P. In number marking languages, $\mathrm{M}^{0}$ often goes unpronounced, silently relating a numeral with the predicate denoted by a noun. In classifier languages, $\mathbf{M}^{0}$ is expressed by classifiers, which transform kind-denoting nouns into predicates whose members may be counted. Our system of number marking contributes non-trivial semantics only in the first case, where nouns are born as predicates. To see how number marking delivers redundant information in a language whose nouns denote kinds, we must first settle on a semantics for number marking. This is the topic of the next section.

\section{The semantics of number marking}

We begin our investigation of counting in natural language by considering number morphology, a phenomenon that ostensibly finds its value on the basis of an evaluation of whether or not some thing numbers (or measures) 1. Sauerland, Anderssen \& Yatsushiro (2005) provide experimental support for a conception of morphological number under which the singular form of a noun requires a singular referent, the semantically weaker plural form allows for either a singular or plural referent, and Heim's (1991) principle of Maximize Presupposition ensures that in the general case morphological number and semantic number (i.e., individual vs. sum reference) align. ${ }^{1}$

We will see, however, that not every instance of a morphologically singular

1 For additional experimental support for this conception of morphological number, see also Pearson, Khan \& Snedeker 2010. 
noun references a single individual. For example, in Turkish and languages like it, any instance of a numeral greater than 'one' requires singular morphology on the co-occurring noun (Farkas \& de Swart 2010; Bale, Gagnon \& Khanjian 2011). Even within English, so-called amount terms like kilo (Lønning 1987) express morphological number, yet their morphology appears to be insensitive to singular vs. plural reference: in a construction such as one kilo of apples, kilo surfaces with singular morphology regardless of the number of individuals referenced (i.e., the number of apples).

Our task is to allow singular-marked nominals to receive a plural interpretation, whether in a Turkish-like language that requires singular nouns with all numerals or in an English-like language whose amount terms resist morphological classification on the basis of how many objects are referenced. Before accounting for these patterns of number marking, we review in more detail the facts to be explained.

\subsection{Background: Diverging patterns of number marking}

Consider two patterns of number marking in the presence of numerals: numerals greater than 'one' combining with plural-marked nouns (e.g., English), and all numerals combining with singular (unmarked) nouns (e.g., Turkish). Supposing number marking finds its value on the basis of one-ness in both types of languages, the pattern in Turkish-like languages poses a serious problem to our conception of morphological number: singular nouns reference pluralities of objects.

The English system, wherein only the numeral one combines with morphologically singular nouns (one boy but not one boys; two boys but not two boy), is likely more familiar. Similar to English, Turkish and languages like it (e.g., Hungarian; Farkas \& de Swart 2010) are number marking: there exists a morphological distinction between singular and plural forms of nouns, and the choice of this morphology is well-defined. In Turkish, the suffix -lar indexes plurality. ${ }^{2}$

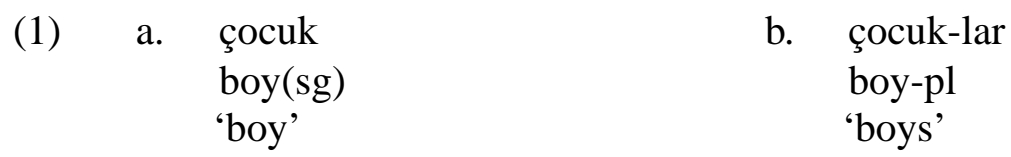

Unlike with English, however, in Turkish-like languages all numerals, crucially those greater than 'one', require singular morphology. Concretely, in Turkish this requirement prohibits plural -lar from occurring in the presence of any numeral.

$$
\begin{aligned}
& \text { a. iki çocuk } \\
& \text { two boy(sg) } \\
& \text { 'two boys' }
\end{aligned}
$$

b. *iki çocuk-lar
two boy-pl

2 All Turkish data in this subsection come from Bale et al. 2011. 
Despite clear reference to more than one individual, i.e., to two boys, the noun çocuk 'boy' in (2a) expresses singular morphology.

Even within English, we find instances of singular morphology where more than one individual is referenced. The cases of interest involve amount terms, words that specify standard measures such as kilo or liter or pound. As with basic nouns like boy, amount terms express number morphology (kilo vs. kilos) and combine with numerals (one kilo vs. two kilos). Given their noun-like behavior, suppose that the system determining number morphology on amount terms is the same as that handling basic nouns. However, one boy references a single boy, whereas in (3a) one kilo of apples references possibly (and probably) more than one apple.

a. one kilo of apples

b. three kilos of apples

In English amount terms have their morphology determined by the co-occurring numeral and not by the number of individuals referenced. In (3a,b), the number of apples referenced is irrelevant to the number marking on kilo. Once again we have an instance where a singular-marked nominal, here involving an amount term, requires a plural interpretation that references more than one individual. The remainder of this section presents a semantic account of number marking meant to yield just this interpretation.

\subsection{Scontras's (2013) proposal}

In an attempt to account for the variation presented in the previous subsection, Scontras (2013) develops a semantics for number marking under which morphological number is divorced from semantic number. Building on the presuppositional account of number marking in Sauerland 2003, Scontras assumes that syntactic number features are hosted in the syntactic head \#, which projects between NP and DP. Morphological number arises as a result of syntactic agreement with \#.

\# comes in two variants: SG and PL. SG presupposes one-ness of the nominal predicate with which it composes, (4a); PL is merely an identity map on predicates, (4b). (For now we leave the measure $\mu$ relevant to the one-ness presupposition of SG in (4a) unspecified.) The principle of Maximize Presupposition (Heim 1991) ensures than whenever SG can be used, it is. In other words, when a singular referent is intended, singular morphology surfaces on the noun used to reference it. Otherwise, PL and its concomitant plural morphology appear.

$$
\begin{array}{ll}
\text { a. } & {[[\mathrm{SG}]]=\lambda \mathrm{P}: \forall \mathrm{x} \in \mathrm{P}[\boldsymbol{\mu}(\mathbf{x})=\mathbf{1}] . \mathrm{P}} \\
\text { b. } & {[[\mathrm{PL}]]=\lambda \mathrm{P} . \mathrm{P}}
\end{array}
$$

Distinct from but related to morphological number, determined by the \# heads SG 
and PL, is semantic number. Semantic plurality is a property of predicates closed under sum formation via the *-operator (Link 1983): the predicate includes members whose proper parts are themselves members of the predicate. In (5a), we have a semantically singular predicate. In (5b) that predicate is closed under sum formation, yielding a semantically plural predicate.

$$
\begin{array}{ll}
\text { a. } & {[[\mathrm{boy}]]=\{\mathrm{a}, \mathrm{b}, \mathrm{c}\}} \\
\text { b. } & {[[* \mathrm{boy}]]=\{\mathrm{a}, \mathrm{b}, \mathrm{c}, \mathrm{a}+\mathrm{b}, \mathrm{a}+\mathrm{c}, \mathrm{b}+\mathrm{c}, \mathrm{a}+\mathrm{b}+\mathrm{c}\}}
\end{array}
$$

Cardinal numerals, those that serve the purpose of counting, are derived from individualdenoting numbers, type $n$. Structurally, numbers occupy the specifier of the functional projection M(easure)P (Hurford 1987); MP projects between NP and DP as in (6) (Ritter 1992).

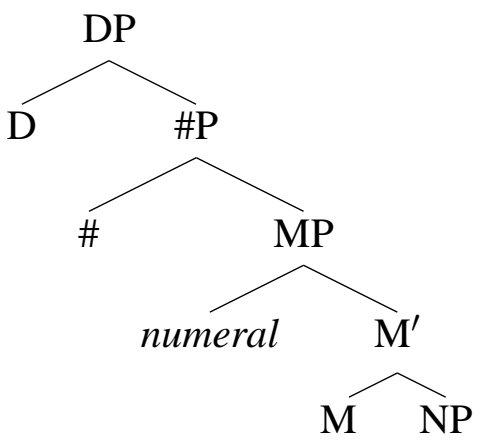

The choice of $\mathrm{M}^{0}$ determines the function of a numeral (e.g., cardinal, ordinal, etc.; Zabbal 2005); cardinal numerals are formed by the $\mathrm{M}^{0}$ head CARD, (7). CARD serves to relate nominal predicates and numerals via the cardinality measure $\mu_{\mathrm{CARD}}$.

$$
[[\mathrm{CARD}]]=\lambda \mathrm{P} \lambda \mathrm{n} \lambda \mathrm{x} . \mathrm{P}(\mathrm{x}) \wedge \mu_{\mathrm{CARD}}(\mathrm{x})=\mathrm{n}
$$

Morphological number marking is determined by the choice of \#, which takes the nominal predicate denoted by MP (type $\langle e, t\rangle$ ) as an argument and checks for the one-ness of this predicate. Concretely, SG (the determinant of singular morphology) checks whether every member of the denotation of a nominal predicate evaluates to 1 with respect to the measure $\mu$ in its presupposition. Variation in patterns of number marking is captured by variation in the selection of the measure against which this one-ness presupposition is checked. We begin with the number marking pattern from Turkish-like languages. 


\subsection{The case of Turkish}

Recall that Turkish and languages like it require singular morphology in the presence of any numeral. To understand how this pattern of number marking arises in our system, consider the structure of a nominal predicate modified by a cardinal numeral, as in (8c).

$$
\begin{array}{ll}
\text { a. } & {[[\mathrm{boy}]]=\{\mathrm{a}, \mathrm{b}, \mathrm{c}\}} \\
\text { b. } & {[[* \text { boy }]]=\{\mathrm{a}, \mathrm{b}, \mathrm{c}, \mathrm{a}+\mathrm{b}, \mathrm{a}+\mathrm{c}, \mathrm{b}+\mathrm{c}, \mathrm{a}+\mathrm{b}+\mathrm{c}\}} \\
\text { c. } & [\text { two CARD } * \text { boy }]]=\{\mathrm{a}+\mathrm{b}, \mathrm{a}+\mathrm{c}, \mathrm{b}+\mathrm{c}\}
\end{array}
$$

Given our semantics for CARD, cardinal numerals serve as restrictive modifiers: they return a subset of a noun's denotation populated by individuals with the appropriate cardinality. By ensuring that every element has the same cardinality, cardinal numerals quantize the members of the resulting denotation. Crucially, every member of a quantized predicate has no parts that are also members of that predicate; in other words, every member of a quantized predicate is a smallest member.

Take two boys in (8c). This predicate is true of three (plural) individuals: $a+b$, $\mathrm{a}+\mathrm{c}$, and $\mathrm{b}+\mathrm{c}$. Each of these individuals has no members which are also in the denotation of two boys. In this way, every member of the predicate two boys is a smallest member of the predicate two boys: every member is an atom relative to the predicate in question. (We leave it to the reader to check that this situation holds for any cardinal numeral.) In Turkish, then, number marking appears to be sensitive not to absolute atomicity (evaluated by, for example, the cardinality measure $\mu_{\mathrm{CARD}}$ ) but rather to relative atomicity: quantized predicates bear singular morphology.

In Turkish the measure relevant to the one-ness presupposition of SG should count the smallest elements, or relative atoms of nominal predicates. We define such a measure in (9).

$$
\begin{aligned}
& \mu_{\mathrm{P}-\text { atom }}(\mathrm{y}) \text { is defined only if } \mathrm{y} \in \mathrm{P} \text {; when defined } \\
& \mu_{\mathrm{P} \text {-atom }}(\mathrm{y})=|\{\mathrm{x} \in \mathrm{P}: \mathrm{x} \leq \mathrm{y} \& \neg \exists \mathrm{z} \in \mathrm{P}[\mathrm{z}<\mathrm{x}]\}|
\end{aligned}
$$

Because numerals quantize nominal predicates, and because every member of a quantized predicate measures $1 \mathrm{P}$-atom, with $\mu_{\mathrm{P} \text {-atom }}$ as the measure relevant to the one-ness presupposition of SG, we predict singular morphology in the presence of any numeral. This is the pattern in Turkish-like languages: number marking is sensitive to the relative atomicity of nominal predicates (via $\mu_{\mathrm{P} \text {-atom }}$ ) and all predicates that are modified by a numeral satisfy the one-ness presupposition of SG by this metric. Concretely, in (8c) every member of the predicate measures 1 two-boy atom; with the Turkish \# heads, defined as in (10), the predicate in (8c) satisfies SG's one-ness presupposition and so SG is used, resulting in singular morphology 
Accounting for counting

on the noun.

Turkish \# heads

a. $\quad[[\mathrm{SG}]]=\lambda \mathrm{P}: \forall \mathrm{x} \in \mathrm{P}\left[\mu_{\mathrm{P}-\text { atom }}(\mathrm{x})=1\right] . \mathrm{P}$

b. $\quad[\mathrm{PL}]]=\lambda \mathrm{P} . \mathrm{P}$

We now turn to the pattern in English.

\subsection{The case of English}

Unlike in Turkish, in English and languages like it only the numeral one requires singular morphology on co-occurring nominals; all other numerals require plural morphology. We therefore have one boy but not one boys, and two boys but not two boy. This pattern arises if we take the cardinality measure $\mu_{\mathrm{CARD}}$ to determine the one-ness presupposition of the morphological singular form (i.e., SG). Consider one boy and two boys in (11).

$$
\begin{array}{ll}
\text { a. } & {[[\text { boy }]]=\{a, b, c\}} \\
\text { b. } & {[[* b o y]]=\{a, b, c, a+b, a+c, b+c, a+b+c\}} \\
\text { c. } & {[[\text { one CARD boy }]=\{a, b, c\}} \\
\text { d. } & [\text { two CARD } * \text { boy }]]=\{a+b, a+c, b+c\}
\end{array}
$$

In (11c), every member of the predicate has cardinality 1. Therefore, SG's presupposition (relativized to $\mu_{\mathrm{CARD}}$ ) is satisfied and so we get singular morphology with one. In (11d), not every member of the predicate has cardinality 1 . In fact, no member does. The one-ness presupposition therefore fails and so we get plural morphology with two (and all other numerals). With $\mu_{\mathrm{CARD}}$ determining the one-ness presupposition of SG, morphological number (SG vs. PL) matches semantic number (*-closure): only when a predicate has not been closed under sum-formation will all of its members have cardinality 1 , necessitating singular morphology.

Relativizing the one-ness presupposition of SG in English to $\mu_{\mathrm{CARD}}$ in all cases will not suffice to handle the data considered in section 2.1 above: basic nouns like boy constitute only part of the picture for English. Recall that amount terms like kilo also display regular number morphology (one kilo of apples vs. two kilos of apples). With amount terms, however, assessing singular morphology on the basis of simple cardinality, i.e., the number of intended referents, fails to predict the facts. To see why, first consider the semantics for amount terms.

Scontras (2013) takes amount terms to be relational nouns, combining first with a nominal predicate and then with a numeral. The result is a set of individuals measuring the extent specified by the numeral; the amount term supplies the appropriate measure. For kilo in (12) this measure is $\mu_{k g}$, the measure in kilograms. 


$$
[[\mathrm{kilo}]]=\lambda \mathrm{P} \lambda \mathrm{n} \lambda \mathrm{x} . \mathrm{P}(\mathrm{x}) \wedge \mu_{k g}(\mathrm{x})=\mathrm{n}
$$

Note that the semantic type given to amount terms, $\langle\langle e, t\rangle,\langle n,\langle e, t\rangle\rangle\rangle$, matches that given to the $\mathrm{M}^{0}$ head CARD in (7). This is no accident: amount terms instantiate the same syntactic category as CARD, projecting MP.

As in the case of CARD, an MP headed by an amount term denotes a nominal predicate, which may then be checked against the one-ness presupposition of SG. Consider what happens with one kilo of apples, assuming that in English the determinant of singular morphology is $\mu_{\mathrm{CARD}} .^{3}$

$$
[[\text { one kilo (of) apples }]]=\lambda \mathrm{x} . * \operatorname{apple}(\mathrm{x}) \wedge \mu_{k g}(\mathrm{x})=1
$$

Like one boy, one kilo of apples denotes a nominal predicate, i.e., a set of individuals. The amount term kilo constrains the denotation of apples on the basis of the kilo measure, $\mu_{\mathrm{kg}}$. One kilo of apples thus denotes the set of apple individuals measuring 1 kilo. But the average apple weighs approximately 0.2 kilos, so in most scenarios the individuals denoted by one kilo of apples will be pluralities, or sums of individuals. In other words, the individuals denoted by one kilo of apples will not have cardinality 1 . Checking such a set against the one-ness presupposition of SG relativized to $\mu_{\mathrm{CARD}}$ therefore fails, and so we incorrectly predict plural morphology on kilo in (13): one kilos of apples.

For our system of number marking to handle both basic nouns and amount terms, the one-ness presupposition of English's SG cannot be invariantly tied to cardinality (and through cardinality to semantic number). However, note that cardinality does yield the correct pattern of number marking in the case of cardinal numerals: in one boy, but not two boys, every individual referenced has cardinality 1 , so we get singular morphology on the noun. Further note that the cardinality measure, $\mu_{\mathrm{CARD}}$, comes specified by CARD in the presence of a cardinal numeral: CARD occupies $\mathbf{M}^{0}$, the head closest to \#. Scontras (2013) claims that in English, the measure specified by $\mathrm{M}^{0}$ determines the measure relevant to the one-ness presupposition of SG.

With an amount term like kilo heading $\mathrm{MP}, \mathrm{M}^{0}$ comes specified for the amount term's measure (e.g., $\mu_{k g}$ ). In (13), every member of the set denoted by one kilo of apples necessarily evaluates to 1 with respect to the kilo measure. With a different numeral, say two, no longer does every member measure 1 kilo; no member does. Here is our pattern of number marking on English amount terms: the measure supplied by the amount term - and not absolute cardinality - determines nominal morphology. In the presence of numerals, singular morphology is checked against

3 Given that the nominal argument of an amount term must be either a bare plural or mass noun, we likely want to amend the semantics in (13) to the following: $\lambda \mathrm{x} . \cup \operatorname{apple}(\mathrm{x}) \wedge \mu_{k g}(\mathrm{x})=1$. We return to this point in section 3.3 below. 
the measure specified by the head closest to \#.

The system of number marking as it is presented in Scontras 2013 yields the desired patterns, but it faces the problem of not being compositional: some sort of magic looks into the semantics of the measure heads and plugs the relevant measure into the one-ness presupposition of SG. We can do better. In order to compositionally attribute the measure internal to $\mathrm{M}^{0}$ to the one-ness presupposition of $\mathrm{SG}$, we must consider what all these measures have in common; we can then hang our system of English number marking on this property of measures.

All measures in $\mathrm{M}^{0}$ are quantity-uniform with respect to the nominal predicate that MP denotes. For a measure to be quantity-uniform with respect to some predicate $\mathrm{P}(\mathrm{QU} P)$, every member of $\mathrm{P}$ must evaluate to the same extent with respect to that measure, (14). Take for example the MP one boy in (11c), repeated in (15).

$$
\begin{aligned}
& \mathrm{QU}_{P}(\mu)=1 \text { iff } \exists \mathrm{n} \forall \mathrm{y}[\mathrm{y} \in \mathrm{P} \rightarrow \mu(\mathrm{y})=\mathrm{n}] \\
& {[[\text { one CARD boy }]]=\{\mathrm{a}, \mathrm{b}, \mathrm{c}\}}
\end{aligned}
$$

In (15) CARD heads MP, and internal to CARD is the cardinality measure $\mu_{\mathrm{CARD}}$. The predicate one boy denotes a set of singular boys. When measured by $\mu_{\mathrm{CARD}}$, every member returns the same value, namely, 1 . With one kilo of apples, kilo heads MP and supplies the kilo measure $\mu_{k g}$; the predicate denotes a set of apple pluralities that each return the same value when measured by $\mu_{k g}: 1$. We leave it to the reader to verify that any measure supplied by $\mathrm{M}^{0}$ will be quantity-uniform with respect to the predicate denoted by MP. Given that the aim is to tie the one-ness presupposition to the measures in $\mathrm{M}^{0}$, all we need do is relativize this presupposition to just those quantity-uniform measures as defined in (14).

$$
\begin{aligned}
& \text { English \# heads } \\
& \begin{array}{l}
\text { a. }[[\mathrm{SG}]]=\lambda \mathrm{P}: \forall \mu \forall \mathrm{x} \in \mathrm{P}\left[\mathrm{QU}_{P}(\mu) \rightarrow \mu(\mathrm{x})=1\right] . \mathrm{P} \\
\text { b. }[[\mathrm{PL}]]=\lambda \mathrm{P} . \mathrm{P}
\end{array}
\end{aligned}
$$

What results is a fully compositional account of English number marking: with cardinal numerals, number marking is sensitive to the quantity-uniform measure $\mu_{\mathrm{CARD}}$, i.e., to the semantic number of nominal predicates. With amount terms, number marking is sensitive to the quantity-uniform measure supplied by the amount term itself, which in effect links number marking to the value of the co-occurring numeral: one takes SG regardless of the number of intended referents. ${ }^{4}$

4 Tying the one-ness presupposition in English to quantity-uniform measures remains an oversimplification. Uli Sauerland (p.c.) points out that there are instances where a quantity-uniform measure does not evaluate to 1 and yet singular morphology is realized on a noun. Consider the MP one twokilo quantity of flour. This predicate denotes a set of individuals all measuring 2 with respect to the kilo measure, so $\mu_{k g}$ should be relevant to number morphology. But despite the fact that not every 


\subsection{Summary}

In this section we have expanded on the semantic account of morphological number developed in Scontras 2013. Morphological number marking finds its value on the basis of the functional head \#, either SG or PL. Singular morphological number, determined by SG, carries with it a one-ness presupposition for the nominal predicate with which it composes: every member of the predicate must evaluate to 1 on the basis of some measure. The selection of the measure relevant to the one-ness presupposition of SG determines the pattern of morphological number observed.

In Turkish-like languages, all numerals require morphologically singular nouns. By tying the one-ness presupposition of SG to a measure in relative atoms, $\mu_{\mathrm{P} \text {-atom, }}$, we generate this pattern. Cardinal numerals quantize their resulting predicates such that every member is a smallest member and therefore the predicate satisfies the one-ness presupposition of SG: no element has a part that is also a member, so every element is a (single) relative atom.

In English-like languages, only the numeral one takes singular morphology. For basic nouns, morphology is determined on the basis of semantic number via the cardinality measure $\mu_{\mathrm{CARD}}$. For the number morphology on amount terms, semantic number is irrelevant; instead, one-ness is assessed relative to the measure supplied by the amount term itself. In both cases, the measure head supplies the measure relevant to the one-ness presupposition of SG. The compositional semantics accesses these measures by virtue of their being quantity-uniform with respect to the nominal predicate denoted by MP. The system defaults to $\mu_{\mathrm{CARD}}$ in the case that MP is not projected, i.e., in a simple DP like the boys.

Crucial to this system is the semantic import of morphological number: the singular form signals one-ness of nominal predicates. In the absence of numerals or amount terms, the singular form implicates semantically singular predicates, i.e., predicates not closed under sum-formation. Number marking languages like English and Turkish contrast with classifier languages, which instead of morphological number make heavy use of classifiers. In light of what we have said about number marking, our task now is to understand its absence in classifier languages.

\section{Number marking and classifiers}

Classifiers are taken to be an epiphenomenon of classifier languages: a closed, contrasting set of morphemes that designate countable units (Greenberg 1972; Allan 1977a,b; Denny 1976, 1979; Adams \& Conklin 1973). Classifier languages are

member of MP evaluates to 1 with respect to $\mu_{k g}$ (none do), we have singular morphology expressed on quantity. The resulting system should therefore prioritize the measure in quantity atoms (itself a quantity-uniform measure) over the measure specified by $\mathrm{M}^{0}$. We leave this step to future work. 
those that require classifiers in the presence of numerals for the purpose of counting the referents of nouns. Consider the obligatory status of the classifier ge in (17).

$$
\begin{aligned}
& \text { san } *(\text { ge }) \text { ren } \\
& \text { three CL people } \\
& \text { 'three people' }
\end{aligned}
$$

Mandarin

Measure heads, both CARD and amount terms like kilo, mirror true classifiers: they are a set of morphemes that mediate the relation between numerals and nouns. In fact, we will show that classifiers are measure heads like CARD and amount terms, and further that any instance of counting (or measuring more broadly) appeals to one of these heads, both in classifier and number marking languages.

Viewed through the lens of the system described in the previous section, classifier languages stand apart because they lack CARD: what number marking languages can do covertly with CARD (i.e., compose numerals with nouns for the purpose of counting), classifier languages must do overtly with a classifier. But there is more to the dissimilarity between classifier and number marking languages, as evidenced by the following cross-linguistic generalizations: First, if a language has obligatory classifiers, then it freely allows bare arguments (Chierchia 1998b); and second, if a language has obligatory classifiers, then it lacks obligatory number marking (Greenberg 1972). Both of these generalizations receive an account once we augment our semantics of number marking with the assumption that nouns in classifier languages refer to kinds, whereas nouns in number marking languages denote predicates. The semantic import of number marking always yields redundant information in a classifier language. We therefore claim that obligatory number marking is only allowed if it delivers otherwise unrecoverable information. To see how this claim falls out within our system, we first consider in more detail the relevant cross-linguistic generalizations concerning classifiers and number marking. We then see how classifiers conform with the syntax and semantics of nominals proposed in the previous section.

\subsection{Cross-linguistic generalizations}

The first generalization concerns the lack of number marking in classifier languages. Greenberg (1972) reproduces the following claim attributed to an unpublished manuscript by Slobin, later appearing in Sanches \& Slobin 1973.

Slobin-Greenberg-Sanches Generalization:

"If a language includes in its basic mode of forming quantitative expressions numeral classifiers, then [...] it will not have obligatory marking of the plural on nouns."

(Greenberg 1972: 286) 
In other words, classifier languages do not have obligatory systems of number marking: if a language requires classifiers in the presence of numerals, morphological number will not be (necessarily) expressed. ${ }^{5}$ Conversely, if a language has obligatory number marking, then it will not have a generalized system of classifiers. Specifying "obligatory" number marking is crucial: the Slobin-Greenberg-Sanches generalization does not rule out number marking altogether in classifier languages, allowing for optional number marking in a classifier language, as with Chinese men or Japanese tati (e.g., Li 1999; Kurafuji 2004).

Knowing what we do about the semantic import of number marking - namely, that it indexes the one-ness of nominal predicates - our task is to understand the connection between classifiers and number marking such that the two are incompatible. Before exploring this connection, however, we consider another property of classifier languages that will quickly become relevant to the task at hand.

In addition to necessitating classifiers for counting, classifier languages freely allow bare nominal arguments: nouns appear bare (i.e., determiner-less) in argument position (cf. dogs in the sentence dogs are widespread). Chierchia (1998b; see also Chierchia 1998a, 2010) provides an account of bare arguments in classifier languages via his Nominal Mapping Parameter, whereby nouns in classifier languages are born argumental, referring at the kind level (for discussion of kind semantics, see Carlson 1977). Contrasting with classifier languages, English and other number marking languages map their nouns to predicates (of type $\langle e, t\rangle$ ), while functional structure (e.g., determiners or other methods of type-shifting) transforms nouns into arguments. ${ }^{6}$

Because nouns are born as kinds in classifier languages, classifiers are required to access the members of a kind for the purpose of counting. A classifier transforms a kind, essentially a name for the maximal plural individual (i.e., the supremum) instantiating that kind, into the set of individuals belonging to the kind. We consider the semantics of classifiers in more detail in the next subsection; for now it suffices to adopt the view under which nouns in classifier languages are kind-denoting unless they appear with a classifier, which shifts kind-denoting nouns into predicates. In number marking languages, nouns are born as predicates and shift to kinds as needed. Thus, bare arguments are restricted in number marking languages: a predicate-denoting noun must shift to an argumental type. In classifier languages bare arguments are freely allowed: a kind-denoting noun is born argumental. To see how this nominal mapping interacts with the Slobin-Greenberg-Sanches generalization, we turn now to the semantics of classifiers.

5 See Doetjes 2012 for a fuller discussion of this generalization and potential counterexamples to it. 6 This description of the Nominal Mapping Parameter is a simplification for the sake of perspicuity; the reader is referred to Chierchia 1998 b for the details. 


\subsection{Classifier semantics}

The structure attributed to classifiers should look familiar from our discussion of Measure Phrases in section 2: classifiers compose first with a nominal and then with a numeral, projecting a classifier phrase (e.g., Li 2011; Jiang 2012; Li \& Rothstein 2012).

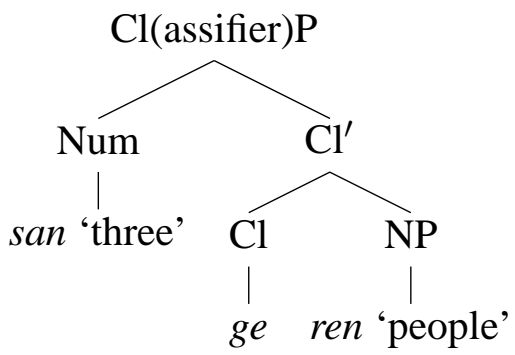

Note the similarity between the classifier phrase in (19) and MP in (6): in both cases the classifier $/ \mathrm{M}^{0}$ heads the structure, intervening between a nominal and a numeral. Semantically, the type we attribute to measure heads also applies to classifiers ( $\mathrm{Li}$ 2011; Krifka 1995). In light of our discussion of nominal mapping from the previous subsection, the only difference between $\mathrm{M}^{0}$ and classifier semantics is that the former composes first with predicates (type $\langle e, t\rangle$ ) whereas the latter composes with kinds (type $k) .^{7}$ A candidate classifier semantics appears in (20a); we repeat the semantics for CARD in (20b).

$$
\begin{array}{ll}
\text { a. } & {[[\mathrm{CL}]]=\lambda \mathrm{k} \lambda \mathrm{n} \lambda \mathrm{x} . \cup_{\mathrm{k}}(\mathrm{x}) \wedge \mu_{\mathrm{CARD}}(\mathrm{x})=\mathrm{n}} \\
\text { b. } & {[[\mathrm{CARD}]]=\lambda \mathrm{P} \lambda \mathrm{n} \lambda \mathrm{x} . \mathrm{P}(\mathrm{x}) \wedge \mu_{\mathrm{CARD}}(\mathrm{x})=\mathrm{n}}
\end{array}
$$

Given the parallels in both structure and semantics between classifiers and measure heads, it seems no great stretch to align the two. This is precisely what we propose: classifiers are yet another instantiation of $\mathrm{M}^{0}$. Counting and measuring, whether in a number marking language like English or a classifier language like Chinese, always appeals to a measure head head that mediates the relation between a nominal and a number-denoting numeral. Finally, we stand to account for the lack of number marking in classifier languages.

7 Assigning to kinds the type $k$ is merely a shorthand; kinds are individuals (or individual concepts) just like the president or John. What sets kinds apart is their ability to serve as the argument of the ${ }^{\cup}$ operator, which returns the members of a kind. See Chierchia 1998b for the details of kind formation. 


\subsection{Linking classifiers, bare arguments, and the lack of number marking}

Having aligned classifier and number marking languages such that both appeal to MP in the formation of a numeral-modified nominal, we now turn to the difference between the two types of languages that precludes obligatory number marking in classifier languages. We begin by recapping the discussion thus far.

Assume a version of the Nominal Mapping Parameter whereby languages either map their nouns to kinds (type $k$ ) or to predicates (type $\langle e, t\rangle$ ) (Chierchia 1998b). In an $\mathrm{N}_{k}$ language, nouns are born argumental and so we predict nouns to freely appear bare, without determiners, in argument positions. However, assuming that counting proceeds over members of a set and that kinds are individuals, classifiers are required in the presence of a numeral to shift the kind-denoting noun to a predicate, that is, a set of individuals (the members of the kind).

Next, consider the role of number marking: number morphology is realized on nouns and gives information about the quality of the nominal denotation. Only when every member of a noun's denotation evaluates to 1 by the relevant measure does singular morphology surface. In an $\mathrm{N}_{\langle e, t\rangle}$ language where nouns denote predicates, number marking is (at least sometimes) informative. For example, in the case of the boy ate the cake, we know on the basis of the singular morphology expressed on boy that the intended referent is in a singular individual, not a plurality: only singular individuals may be included in the denotation of the singular-marked boy because of the one-ness presupposition of SG. In this way, number marking in an $\mathrm{N}_{\langle e, t\rangle}$ language provides information about the denotation of nominals that would otherwise be unrecoverable from the larger linguistic structure; only the number marking clues us in to the number of boys referenced.

In a classifier language, the singular/plural distinction is uninformative: nouns in these languages denote kinds, and (intensionalized) individuals are not something that can be closed under sum-formation. Moreover, kinds are concepts that require more than one instantiation, so it should never be the case that the kind itself has cardinality 1 (Chierchia 1998b). Evaluating the one-ness of a kind therefore necessarily fails, owing both to the type-mismatch between predicate-selecting \# heads and to the conceptual difficulty associated with evaluating the one-ness of a kind. Thus, indexing kind-denoting nouns with number morphology is nonsensical. In the general case, then, introducing a system of number marking into a $\mathrm{N}_{k}$ language makes no semantic contribution: nouns denote kinds and so the one-ness presupposition always fails (assuming it could apply at all), necessitating plural morphology in all cases.

Note nominal predicate semantics may be derived in a classifier language via a numeral-classifier construction: the role of a classifier is to mediate between a noun's kind referent and a numeral, forming a predicate of individuals (type 
$\langle e, t\rangle)$. However, in any such construction, the resulting denotation will be quantityuniform, determined by the numeral present. For example, the predicate one-CLperson/people will denote the quantity-uniform set of people pluralities, each with cardinality 1 ; the semantics for this construction and its parts appears in (21).

$$
\begin{aligned}
& \text { yi ge ren 'one person' } \\
& \text { a. } \quad[[y i]]=1 \\
& \text { b. } \quad[[g e]]=\lambda \mathrm{k} \lambda \mathrm{n} \lambda \mathrm{x} . \cup \mathrm{k}(\mathrm{x}) \wedge \mu_{\mathrm{CARD}}(\mathrm{x})=\mathrm{n} \\
& \text { c. } \quad[\text { ren }]]=\cap \text { person (i.e., the people kind) } \\
& \text { d. }[\text { yi ge ren }]]=\lambda \mathrm{x} \text {. person }(\mathrm{x}) \wedge \mu_{\mathrm{CARD}}(\mathrm{x})=1
\end{aligned}
$$

The semantic contribution of number morphology on a derived predicate like in (21) is redundant: the numeral delivers the information that the resulting denotation is both quantity-uniform and has members all with cardinality 1 . Number morphology on such a derived predicate would therefore be uninformative - the information it could convey is already present in the numeral 'one' (and similarly with all other numerals; in three-CL-person the numeral 'three' clues us in to the fact that more than one person is referenced). We see that in a $\mathrm{N}_{k}$, i.e., a classifier language, number morphology fails to contribute meaningful information both in the general case of kind-denoting bare nouns and in the case of derived nominal predicates.

These facts lead to the following constraint, meant to explain the lack of obligatory number marking in classifier languages: only allow a system of number marking in a language if there are instances where the system delivers otherwise unrecoverable information (about nominal denotations). We have seen that in $\mathrm{N}_{\langle e, t\rangle}$ languages there are cases, i.e., non-quantified nominals, where number morphology is informative. We therefore correctly predict the presence of number marking in such a language. In $\mathrm{N}_{k}$ languages, either the noun refers directly to a kind and is not eligible to be checked by the one-ness presupposition of singular morphology, or a numeral-classifier construction derives a nominal predicate and the numeral itself provides the information about one-ness that number morphology would have delivered. Therefore, given the constraint just stated, in $\mathrm{N}_{k}$ languages we predict the absence of obligatory systems of number marking. Fig. 1 diagrams the implicational connections that lead to this conclusion.

First, the Nominal Mapping Parameter determines whether a language maps its nouns to kinds or to predicates. If the former holds, classifiers are required for the purpose of counting with numerals. However, once there is a generalized classifier system, number marking loses its informativity and so obligatory number marking is ruled out. If the Nominal Mapping Parameter has a language map its nouns to predicates, number marking stands to provide information about the one-ness of these nominal predicates and so number marking is allowed. 


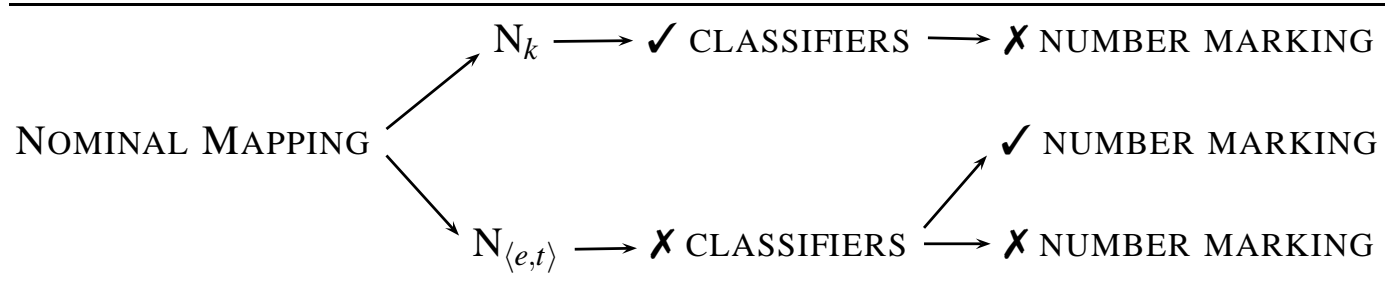

Figure 1 Relating the Nominal Mapping Parameter and number marking.

Note that we do not necessitate number marking in $\mathrm{N}_{\langle e, t\rangle}$ languages, which map their nouns to predicates; we merely rule out obligatory number marking in $\mathrm{N}_{k}$ languages. Our typology therefore predicts languages that we have heretofore not considered: ones in which nouns map to predicates, type $\langle e, t\rangle$, thus precluding classifiers, but in which number marking is also absent. In other words, we predict languages that lack both classifiers and obligatory number marking. Fortunately, such languages are attested (e.g., Dëne Sưłiné, Wilhelm 2008; Tagalog, Doetjes 2012).

One last aspect of the implications diagramed in Fig. 1 warrants further scrutiny: we have said that classifiers are required in $\mathrm{N}_{k}$ languages to retrieve the members of kind-denoting nominals for the purpose of counting. However, we have aligned true classifiers with all measure heads, including CARD. Functionally, classifiers and CARD serve a similar purpose: to mediate the relation between numerals and nouns. Classifiers perform the added step of accessing the members of a kind. Now we return to the point that began this section: what number marking languages may do covertly with CARD, classifier languages must do overtly with classifiers. So what prohibits a null measure head like CARD from entering into the functional lexicon of classifier languages? While the answer to this question requires future study, we offer the following observation, which will likely constrain the set of possible explanations.

Classifiers and CARD differ in two ways. First, classifiers are overt while CARD is silent. Second, classifiers take a kind-denoting argument, whereas CARD selects for predicates. Could these differences be related? Consider the possibility that only covert measure heads like CARD compose with predicates, whereas overt measure heads necessarily compose with kinds. In fact, the other type of measure heads we have considered - amount terms - supports this link between phonologically realized measure heads and kind-selection.

In our investigation of amount terms, we focused on pseudo-partitive constructions wherein an amount term composes directly with a noun, i.e., it takes the noun 
as an argument. ${ }^{8}$ In a pseudo-partitive, the nominal argument of an amount term is restricted to bare plurals and mass nouns, i.e., to names of kinds (Carlson 1977; Chierchia 1998b). Amount terms then align with classifiers to the exclusion of CARD: the former take kind-denoting arguments while CARD composes with a predicate. Building this distinction into the lexical entries for our measure heads, we arrive at the following semantics:

The semantics of measure heads

a. $[[\mathrm{CARD}]]=\lambda \mathrm{P} \lambda \mathrm{n} \lambda \mathrm{x} . \mathrm{P}(\mathrm{x}) \wedge \mu(\mathrm{x})=\mathrm{n}$

b. $\quad[$ CL $/$ amount term $]]=\lambda \mathrm{k} \lambda \mathrm{n} \lambda \mathrm{x} .{ }^{\cup} \mathrm{k}(\mathrm{x}) \wedge \mu(\mathrm{x})=\mathrm{n}$

We see, then, that only covert CARD selects for predicates; overt classifiers and amount terms compose with kinds. While the reason why overt measure heads should select for kinds and covert ones for predicates remains an open question, this tendency stands to clarify the implication between nominal mapping and the presence/absence of classifiers in Fig. 1. $\mathrm{N}_{k}$ languages lack covert measure heads like CARD because their nouns, the arguments of measure heads, denote kinds, not predicates, and overt measure heads are required in the presence of kind-denoting nouns. In an $\mathrm{N}_{\langle e, t\rangle}$ language, nouns denote predicates at base and so we require a covert, predicate-selecting measure head like CARD to compose with them.

\section{Discussion}

Our investigation of counting in natural language focused first on number marking languages like English or Turkish where numerals directly influence the number morphology expressed on nominals. We then considered the semantics of numerals and counting in classifier languages like Mandarin Chinese, pointing to the striking similarity in structure and semantics between counting in number marking and in classifier languages, but taking special notice of the differences. We have accomplished two things. First, we improved upon the semantics of number marking developed in Scontras 2013, accounting for distinct patterns of number marking in the presence of numerals both within and across languages. Second, we used the semantics of number marking to inform the Slobin-Greenberg-Sanches generalization, which precludes obligatory number marking in classifier languages.

The resulting account imports two assumptions from Scontras 2013: 1) numerals denote numbers, type $n$, and compose with nouns only indirectly via functional structure headed by M(easure); and 2) morphological number is determined by the

8 Pseudo-partitives contrast with true partitives, where an amount term composes with a prepositional phrase (see, e.g., Selkirk 1977 for discussion); the amount term does not take the noun as an argument, but rather is modified by the PP. 
head of \#P, either SG or PL, an identity map on nominal predicates:

$$
\begin{array}{ll}
\text { a. } & {[[\mathrm{SG}]]=\lambda \mathrm{P}: \forall \mathrm{x} \in \mathrm{P}[\boldsymbol{\mu}(\mathbf{x})=\mathbf{1}] . \mathrm{P}} \\
\text { b. } & {[[\mathrm{PL}]]=\lambda \mathrm{P} . \mathrm{P}}
\end{array}
$$

The morphological singular, SG, carries a one-ness presupposition: every member of the nominal predicate must evaluate to 1 with respect to some relevant measure $\mu$. The ways that languages specify the measure relevant to the one-ness presupposition of SG determine the patterns of number marking that result. In Turkish and other languages that require singular nouns with all numerals, SG evaluates its presupposition on the basis of relative atomicity; numeral-modified nominals are quantized such that every member of the predicate is a smallest member, so we correctly predict SG with all numerals. In English, SG checks one-ness on the basis of quantity-uniform measures: with cardinal numerals, this measure is simple cardinality, and with amount terms like kilo, this measure is supplied by the amount term itself. Thus, with cardinal numerals English number marking is sensitive to the number of intended referents, but with an amount term like kilo the number of kilos the intended referent weighs (and not the singularity or plurality of that referent) determines nominal morphology.

After tying number marking to an evaluation of the one-ness of nominal predicates, we then considered the lack of number morphology in classifier languages. Assuming Chierchia's (1998b) Nominal Mapping Parameter, whereby nouns in classifier languages reference kinds (and not predicates as in number marking languages), we find a ready explanation for the absence of number marking in these languages: number morphology, which is sensitive to the structure of a predicate denotation, makes no meaningful contribution in a language where nouns denote kinds. Even derived nominal predicates (i.e., numeral-classifier-noun constructions) do not benefit from number morphology: whatever information morphological number could deliver about the one-ness of the derived predicate, the numeral contributes already. We therefore conclude that systems of number marking are allowed only in languages where the number morphology stands to deliver information that would otherwise be unrecoverable from the broader linguistic structure. This constraint permits number marking in languages like English that map their nouns to predicates, and precludes number marking in classifier languages like Chinese that map their nouns to kinds.

While the focus of this study has been the semantics of counting together with its implications for morphological number marking, the claims put forth carry consequences for theories of measurement more broadly. We implicitly took kilo to stand in for all measure terms, but distinct subclasses of measure terms have been identified: amount terms (e.g., kilo; Lønning 1987), container nouns (e.g., 
Accounting for counting

glass; Partee \& Borschev 2012), and English-style classifiers (e.g., grain; Chierchia 1998a), to name just three. The next step is to see how these subclasses of measure terms behave within the proposed framework, and whether they in fact possess distinct semantics.

\section{References}

Adams, Karen L. \& Nancy F. Conklin. 1973. Toward a natural theory of classification. In Claudia Corum, Thomas Cedric Smith-Clark \& Ann Weiser (eds.), Annual Meeting of the Chicago Linguistic Society (CLS) 9, 1-10. Chicago: Chicago Linguistic Society.

Allan, Keith. 1977a. Classifiers. Language 53(2). 285-311.

Allan, Keith. 1977b. Singularity and Plurality in English Noun Phrases: A Study in Grammar and Pragmatics: University of Edinburgh dissertation.

Bale, Alan, Michaël Gagnon \& Hrayr Khanjian. 2011. Cross-linguistic representations of numerals and number marking. In Nan Li \& David Lutz (eds.), Semantics and Linguistic Theory (SALT) 20, 582-598. Ithaca, NY: CLC Publications.

Carlson, Gregory. 1977. Reference to Kinds in English: University of Massachusetts at Amherst dissertation.

Chierchia, Gennaro. 1998a. Plurality of mass nouns and the notion of 'semantic parameter'. In Susan Rothstein (ed.), Events and Grammar, 53-103. Dordrecht: Kluwer Academic Publishers.

Chierchia, Gennaro. 1998b. Reference to kinds across languages. Natural Language Semantics 6. 339-405.

Chierchia, Gennaro. 2010. Mass nouns, vagueness and semantic variation. Synthese 174. 99-149.

Denny, J. Peter. 1976. What are noun classifiers good for? In Annual Meeting of the Chicago Linguistic Society (CLS) 12, 122-132. Chicago: Chicago Linguistic Society.

Denny, J. Peter. 1979. The 'extendedness' variable in classifier semantics: Universal features and cultural variation. In Madeleine Mathiot (ed.), Ethnolinguistics: Boas, Sapir, and Whorf Revisited, 99-119. The Hague: Mouton.

Doetjes, Jenny. 2012. Count/mass distinctions across languages. In Claudia Maienborn, Klaus von Heusinger \& Paul Portner (eds.), Semantics: An International Handbook of Natural Language Meaning, vol. III, 2559-2580. Berlin: de Gruyter.

Farkas, Donka F. \& Henriëtte E. de Swart. 2010. The semantics and pragmatics of plurals. Semantics and Pragmatics 3. 1-54.

Greenberg, Joseph. 1972. Numeral classifiers and substantival number: Problems in the genesis of a linguistic type. Working Papers on Language Universals 9. 
1-39. Reprinted in A. Makkai et al. (eds.), Linguistics at the Crossroads. Lake Bluff, Ilinois: Jupiter Press, 1977, 276-300.

Heim, Irene. 1991. Artikel und definitheit. In Arnim von Stechow \& Dieter Wunderlich (eds.), Semantik: Ein Internationales Handbuch der Zeitgenössischen Forschung, 487-535. Berlin: de Gruyter.

Hurford, James R. 1987. Language and Number: The Emergence of a Cognitive System. Oxford: Blackwell.

Jiang, L. Julie. 2012. Nominal Arguments and Language Variation: Harvard University dissertation.

Krifka, Manfred. 1995. Common nouns: A contrastive analysis of Chinese and English. In Gregory N. Carlson \& Francis Jeffry Pelletier (eds.), The Generic Book, 398-412. Chicago: The University of Chicago Press.

Kurafuji, Takeo. 2004. Plural morphemes, definiteness, and the notion of semantic parameter. Language and Linguistics 5(1). 211-242.

Li, Xu-Ping. 2011. On the Semantics of Classifiers in Chinese: Bar Ilan University dissertation.

Li, Xu-Ping \& Susan Rothstein. 2012. Measure readings of Mandarin classifier phrases and the particle de. Language and Linguistics 13(4). 693-741.

Li, Yen-Hui Audrey. 1999. Plurality in a classifier language. Journal of East Asian Linguistics 8(1). 75-99.

Link, Godehard. 1983. The logical analysis of plurals and mass terms. In Rainer Bäuerle, Christoph Schwarze \& Arnim von Stechow (eds.), Meaning, Use, and Interpretation of Language, 302-323. Berlin: de Gruyter.

Lønning, Jan Tore. 1987. Mass terms and quanitification. Linguistics and Philosophy 10(1). 1-52.

Partee, Barbara H. \& Vladimir Borschev. 2012. Sortal, relational, and functional interpretations of nouns and Russian container constructions. Journal of Semantics 29. 445-486.

Pearson, Hazel, Manizeh Khan \& Jesse Snedeker. 2010. Even more evidence for the emptiness of plurality: An experimental investigation of plural interpretations as a species of implicature. In Nan Li \& David Lutz (eds.), Semantics and Linguistic Theory (SALT) 20, 489-508. Ithaca, NY: CLC Publications.

Ritter, Elizabeth. 1992. Cross-linguistic evidence for number phrase. Canadian Journal of Linguistics 37. 197-218.

Sanches, Mary \& Linda Slobin. 1973. Numeral classifiers and plural marking: An implicational universal. Working Papers in Language Universals 11. 1-22.

Sauerland, Uli. 2003. A new semantics for number. In Robert B. Young \& Yuping Zhou (eds.), Semantics and Linguistic Theory (SALT) 13, 258-275. Ithaca, NY: CLC Publications.

Sauerland, Uli, Jan Anderssen \& Kazuko Yatsushiro. 2005. The plural is semanti- 
Accounting for counting

cally unmarked. In Stephan Kesper \& Marga Reis (eds.), Linguistic Evidence: Empirical, Theoretical and Computational Perspectives, Berlin: Mouton de Gruyter.

Scontras, Gregory. 2013. A unified semantics for number marking, numerals, and nominal structure. In Emmanuel Chemla, Vincent Homer \& Grégoire Winterstein (eds.), Proceedings of Sinn und Bedeutung 17, 545-562.

Selkirk, Elisabeth. 1977. Some remarks on noun phrase structure. In Peter W. Culicover, Thomas Wasow \& Adrian Akmajian (eds.), Formal Syntax, 285316. New York: Academic Press.

Wilhelm, Andrea. 2008. Bare nouns and number in Dëne Sųłiné. Natural Language Semantics 16. 39-68.

Zabbal, Youri. 2005. The syntax of numeral expressions. MS, University of Massachusetts at Amherst.

\footnotetext{
Gregory Scontras

Department of Linguistics

Harvard University

Boylston Hall, 3rd Floor

Cambridge, MA 02138

scontras@fas.harvard.edu
} 